\title{
Reflexões sobre a violência, autoridade e autoritarismo
}

\author{
Emilio E. Dellasoppa
}

Lo ominoso es aquella variedad de loterrorifico que se remonta a lo consabido de antiguo, a lo familiar desde hace largo tiempo.

(Sigmund Freud)
Nossa intenção neste ensaio é explorar as derivações que possam se apresentar a partir de uma série de artigos escritos por Guillermo O’Donnell, $(1979,1986,1988)$ provocativamente comparativos, especialmente entre Argentina e Brasil, produzidos em um contexto marcadamente autoritário: o de incipiente início de um processo de transição democrática em nossos sofridos países.

Resulta interessante nestes momentos, em que os processos de transição se alastram no tempo, pensar novamente os alcances de suas colocações relativas ao "autoritarismo socialmente implantado", procurando investigar relações com outros conceitos e problemas num contexto político radicalmente diferente daquele que originou essas reflexões. Porém, nosso questionamento se origina em um problema específico, que é o da resistência verificada na sociedade brasileira à implantação dos direitos humanos para o conjunto da população, em contraste com a que seria uma relativa aceitação de sua vigência quando se tratava do caso de militantes políticos, geralmente oriundos dos setores médios; ou seja, como mostra Paulo Sérgio Pinheiro (1981, p. 31), somente nestas circunstâncias o problema dos direitos humanos atinge o debate público.

Nossa interrogação aponta no sentido de investigar a persistência do autoritarismo, questão da qual as colocações de O'Donnell exploram alguns importantes aspectos. Como assinala Carlos Altamirano (1985, p. 96), a permanência desta questão suscitada ao debate nos piores momentos dos regimes autoritários leva necessariamente à necessidade de aprofundar o debate para além das caracterizações dos regimes que o representaram, embrenhando-nos nas complexas relações entre os níveis micro e macro da sociedade, e ainda ao nível das disposições pessoais socialmente significantes (Osterreich, 1985, p. 97).

\section{LOCALIZAÇĀO DO AUTORITARISMO SOCIALMENTE IMPLANTADO}

Se lembramos os usos mais ou menos estabelecidos do termo (Stoppino, 1986, p. 94), encontramos a referência a uma tipologia ou estrutura dos sistemas políticos, a disposições psicológicas a respeito do poder ou a ideologias políticas. Resulta interessante pensar como e onde O'Donnell localiza esse autoritarismo socialmente implantado. Em primeiro lugar, ê utilizado como elemento de caracterização da sociedade brasileira na
EMILIO E. DELLASOPPA é pós-graduando em Ciência Polltica e consultor do Núcleo de Estudos da Violência da Universidade de São Paulo. 
Tropas na rua em Córdoba, Argentina, 1971; general Lanusse chega ao poder análise comparativa, especialmente quando é observada em comparação à sociedade argentina (1986, pp. 140-1), estando a análise centrada nos processos dos regimes autoritário-burocráticos que ambos os países suportaram. Mais ainda, nas características que a repressão dos setores militantes e populares assumiu em cada um desses países, marcadamente mais violenta precisamente no país mais igualitário, a Argentina (voltaremos $\mathrm{a}$ isto mais adiante).

Em definitivo, o que interessa das colocações de O'Donnell neste ponto é ele afirmar que o autoritarismo foi socialmente implantado pela sociedade e pelo Estado, em um contexto de uma sociedade política estreita (muito mais que a Argentina), com a própria sociedade profundamente șerializada e hierarquizada, e onde o papel do Estado se apresentava sempre se sobrepondo à sociedade. Neste momento é importante chamar a atenção sobre a caracterização do autoritarismo implantado na sociedade brasileira. De acordo com o sugerido pelo autor, poderíamos talvez extrapolar suas conclusões encontrando uma implantação do autoritarismo em níveis múltiplos, seja tanto o nível das instituições como até o nível dos indivíduos, no que diz respeito a suas "disposições pessoais socialmente relevantes"'? Poderíamos inclusive pensar que esse autoritarismo é implantado mediante mecanismos que implicam diferentes níveis de legitimação que são colocados em prática por todas as classes ou setores sociais brasileiros? Será que esse autoritarismo socialmente implantado poderia ser assimilado sem esforço a um verdadeiro "universo simbólico" (no sentido de Berger e Luckmann) que é compartilhado por setores muito expressivos não só do Estado como da sociedade brasileira? Em que medida a frase "Eu já fui negro,e sei o que isso significa" forma parte da relação que setores da sociedade brasileira mantêm com os elementos autoritários (dos quais o racismo é um aspecto) dos seus universos simbólicos? No decorrer do trabalho tentaremus analisar essas questões.

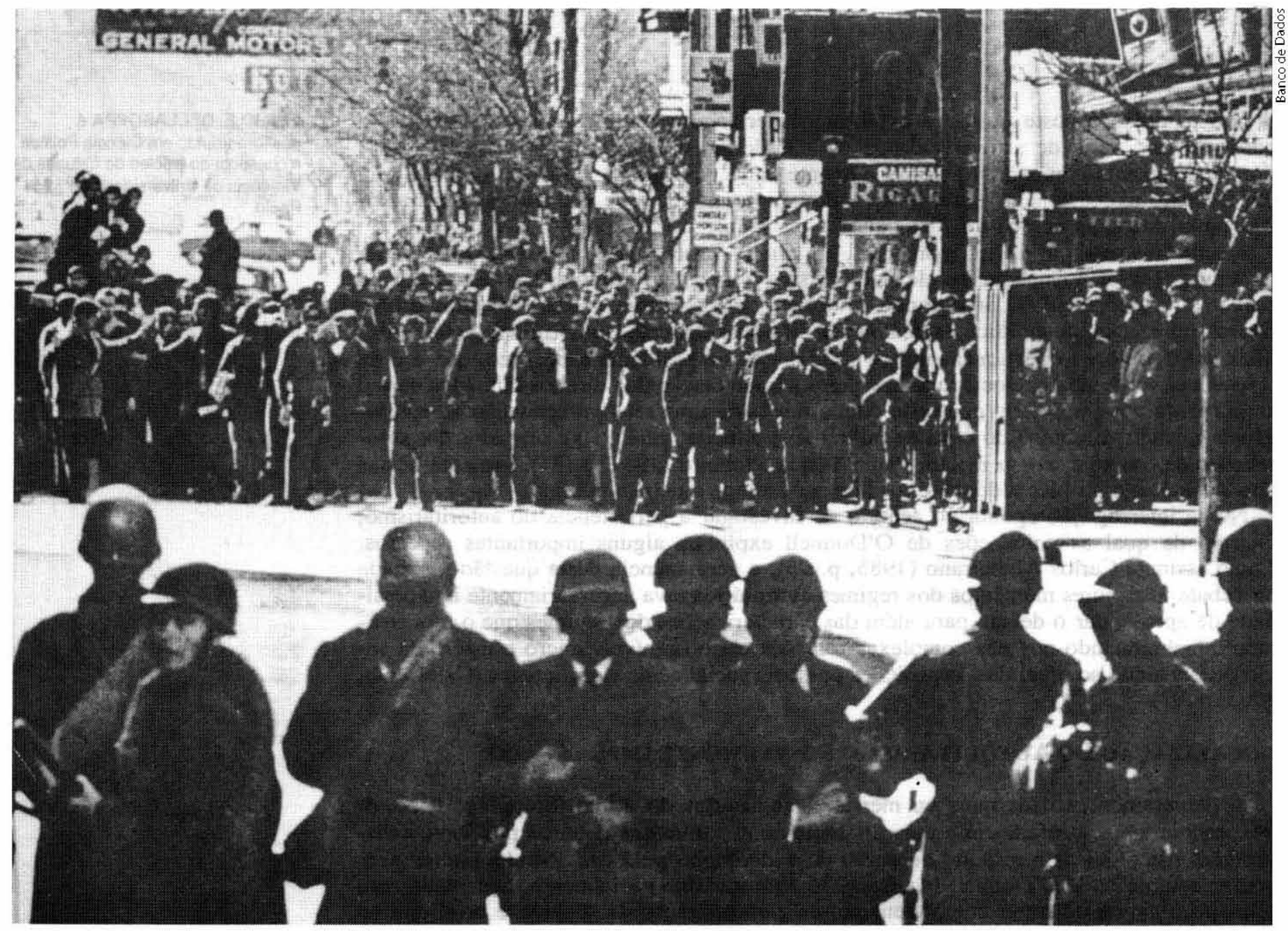




\section{Autoritarismo E ViolênCia Comparativos}

A magnitude do autoritarismo socialmente implantado no Brasil assume características tais que para O'Donnell de alguma maneira impermeabiliza o estado autoritário contra os embates dos (pequenos) grupos que o enfrentavam desde o projeto da revolução ou da simples contestação. E assim mesmo responsável pela reduzida dimensão comparativa do total das vítimas da repressão no Brasil( ${ }^{(1)}$. Porém, para O'Donnell a violência aparece no tecido da sociedade brasileira com características protopolíticas, expressão multifacetada de uma ordem imposta nas favelas, na pobreza, no desemprego, na inexistência ou descumprimento dos direitos trabalhistas e dos outros. Comparativamente despolitizados, os setores populares brasileiros acabam exercendo contra eles mesmos a violência da escassez internalizada ${ }^{(2)}$, e não há lança de Ulisses para curar essas feridas.

Endêmica, no marco da cordialidade indiferente, a violência brasileira diferencia-se radicalmente da argentina. Esta última não pode ser simplesmente decapitada na figura das organizações ou dos militantes pela violência maior do regime autoritário; teve que ser perseguida no próprio tecido social. O que surpreende é que dentro da própria sociedade surgem focos de repressão secundários que vibram em consonância com o autoritarismo do regime: como O'Donnell assinala, os kapos surgem por tudo quanto é lugar, a repressão muda a estrutura das relaçōes de poder dentro das instituições e atinge ainda, na figura de focos menores que propagam a vibração repressiva, os âmbitos de socialização: a família, a escola, o trabalho.

Quebrada pela repressão e pelo medo, a sociabilidade colapsa: ainda hoje, muitos dos atingidos não têm conseguido recuperar os níveis de relacionamento social que existiam antes dos anos do último regime militar, empobrecimento reforçado pela aguda crise econômica que se prolonga durante anos.

Sociedade transpassada por representações de antinomias, peronismo-antiperonismo, imperialismo-naçäo, povo-antipovo, a Argentina conhece nos anos 70 uma falência do coletivo social, e assiste a uma coalescência dos grupos e setores sociais ligados à violência em torno de dois grandes eixos: um, estruturado em torno da violência do regime militar; o outro, dos alvos a serem reprimidos, cada vez com menores possibilidades de ataque e resistência.

Essas características tão diferentes das duas sociedades apontam para a que talvez seja a diferença mais marcante entre as duas violências autoritárias. A violência do regime argentino não tinha, por vocação e por definição, nenhum limite. A frase "isto não tem limites", cunhada expressando a admiração dos próprios executores pelas possibilidades sempre plus ultra de seus respectivos aparelhos repressivos ${ }^{(3)}$, mostra cabalmente o processo de "fractalização"(4) das instâncias do exerć́cio repressivo, repetindo incessantemente a privatização e antinomização que tinham caracterizado o processo polf́tico argentino global. Isto, que implica finalmente em uma perda de controle das instâncias superiores sobre o processo repressivo global, pode considerar-se uma diferença sensível com o caso brasileiro, onde as tentativas de autonomização e ultrapassagem de certos limites foram sumariamente reprimidas.

Paradoxalmente, talvez o próprio conteúdo autoritário socialmente implantado e suas peculiares características sociais tenham preservado o Brasil de um processo tão traumático quanto o argentino. Porém, cabe retomar a pergunta de O'Donnell e inquirir o porquê do êxito do regime em tornar tanto mais autoritária a sociedade argentina, e como aconteceu tão facilmente o processo de difusão do autoritarismo nos microcontextos e nos âmbitos de socialização. Talvez aprofundando a forma de implantação do autoritarismo na sociedade argentina possamos avançar na compreensão do autoritarismo brasileiro, e para isso tentaremos analisar e comparar concepções de ordem e autoridade no âmbito de sociedades autoritárias como as que estamos considerando.

\section{AUTORIDADE E AUTORITARISMo}

Uma das obsessões dos regimes militares, levada no caso argentino quase ao paroxismo, mas presente também em diferentes graus em todos os outros, foi a implantação da ordem e da autoridade. No caso argentino especificamente, como afirma O'Donnell, esta visão da autoridade “(...) não podia ser mais vertical, autoritária e negadora da autonomia daqueles que pretendeu submeter e nem conseguiu, apesar do tom paterna-
1 Na Argentina, foram mortas ou desapareceram 1150 pessoas por cada miIhăo de habitantes. No Brasil, esse mesmo número năo chega a 3.

2 Segundo o Sartre da Crftica da razáo dialética, a violência é a "estrutura da açăo humana sob o reino do maniquelsmo e no quadro da escassez". A quetsio e ulisses os do proprio Sartre no prefácio ao livro de F. Far tre no prefácio ao livio de $F$. Fanon $O$ condenados da terra.

3 Expressão favorita dos integrantes (quase sem distinçăo de hierarquia) do Grupo de Tarefa constituldo na Es cuela de Mecanica de la Armada en cues, 1976-83. Geraln aplicava-se depois dos golpes exitoso - quanto mais audaciosos mais ilimitados - desferidos contra a guerrilha ou contra seus próprios aliados de outras Forças.

4 Usado em sentido metaforico. Originariamente, o termo significa que cabe esperar uma estrutura completa em qualquer escala de ampliaçăo. Ou seja: a complexidade se mantém quando passamos do macro ao micro.

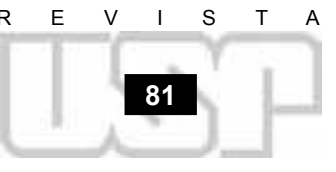


Uma das obsessões dos

regimes militares, levada

no caso argentino quase

ao paroxismo, mas presente

também em diferentes graus

em todos os outros, foi a

implantação da ordem e da

autoridade. No caso

argentino, como afirma

O'Donnell, esta visão de

autoridade "não podia ser

mais autoritária..." lista com que revestia seus argumentos, ocultar a imensa violência, não sơ física, sobre a que se sustentava"' $(1988$, p. 40$)$.

Talvez resulte paradoxal, mas sobre as palavras do autor a respeito da visão de autoridade destes regimes (apesar de referir-se à Argentina, uma extrapolação não parece descabida) parecem pertinentes algumas reflexões de Hannah Arendt, especialmente aquelas que levantam a questão do "desaparecimento" da autoridade no mundo moderno. Sem espaço para relembrar aqui as argumentações desta autora(5), devemos concordar que, pelo menos ao nível conceitual, assistimos a uma verdadeira crise e até a uma mutação deformante no paradigma da autoridade, que atinge suas próprias raízes. Obviamente não se trata de uma crise nova, mas que se encontra no âmago da modernidade, a partir do momento em que os elementos integrantes do

conceito de autoridade, tal como expressado durante a antigüidade, se apresentam como “(...) transliterados na sintaxe política do Estado moderno, sofrendo uma série de mudanças e de torsões que não impedem porém de reconhecer a estrutura da autoridade reduzida a uma mera forma - também no interior da secularização (...)" (Carlo Galli, 1988 , p. 23). Não se trata aqui só de uma autoridade concebida em termos de legitime Herschaft - salvo quiçá nas cabeças nada weberianas de alguns teóricos do regime -, mas da pretensa recuperação de algumas das características do conceito de autoridade pré-moderno e anterior à sua própria crise, que na verdade configuram sua mais completa negação.

Nada mais longínquo que o conteúdo moderno da autoridade do sentido de permanência e continuidade de uma ordem social, de transcendência como criação e garantia de uma ordem, de autoridade como fundamento e diferença do poder, do caráter afirmativo do augere que incrementa o mesmo. O momento fundacional não aparece como tal mas como ruptura de uma ordem, como instância revolucionária de puro poder sem autorictas, pretendendo apropriar-se da autoridade para um Estado que apenas consegue implementar uma forma deformada do augere, aquela que reduz o incremento institucional a simples projeto econômico de desenvolvimento: o fundamento transcendente aparece substituído pela necessidade de resolução de um problema vital da sociedade, a construção sempre aumentada da res-publica aparece desta maneira reduzida a uma serialização problemática onde o econômico, o social e o político são fragmentados na ilusão do restabelecimento da ordem e da autoridade. O projeto piramidal persiste, mas o fundamento transcendente, que foi a sua pedra fundacional até a modernidade, não existe mais para sustentar a autoridade.

Com referência a este ponto, cabe assinalar que ele foi muito mais relevante no caso de regimes como o de Onganía na Argentina (1966-70), com influências do corporativismo católico. Gestos como o de consagrar a República à Virgem de Luján (mais ou menos o equivalente de N. Senhora de Aparecida) explicam-se no contexto de uma concepção de autoridade que procura restabelecer o elo perdido entre autoridade, religião e tradição, recolocando a fonte da autoridade em um ponto transcendente por cima do topo da pirâmide. A leitura do processo de secularização como um decréscimo de autoridade e sua identificação como a causa da maior parte dos problemas do país levou os regimes militares a intentos cada vez mais violentos de restabelecimento da autoridade perdida. A convicção de que somente o restabelecimento da relação ordem-obediência poderia resolver os problemas da sociedade levou a uma identificação cada vez maior de autoridade com violência, baseada talvez, como Arendt assinala, na percepção de que, como a violência faz as pessoas obedecerem, então violência é autoridade (Arendt, 1977, p. 102). Todos os regimes autoritários, sem exceção, têm identificado violência com autoridade, sem perceber que, nunca conseguindo restabelecê-la talvez pelo seu próprio esvair-se como conceito na nossa época, limitavam-se a afirmar que o modo possível de existência da sociedade passava por um marco autoritário. 

AS Tramas do Cotidiano E
OS Grandes Cenários

Quando se intenta estabelecer de alguma maneira as diff́ceis, porém imprescindíveis, relações entre os grandes cenários da política e do Estado com o nível das inter-relações sociais mais elementares e ainda com as disposições pessoais socialmente significantes, deparamos imediatamente com as dificuldades inerentes à complexidade própria dos sistemas que se estabelecem quando se tenta juntar esses níveis de análise.

Na metáfora organicista está implícita a atitude cirúrgica que busca extirpar o mal da sociedade mediante a cirurgia corretiva quando não profilática -, e ainda determinado o sentido da intervenção: desde as estruturas repressivas do Estado até as mais delicadas tramas da sociabilidade e da vida pessoal, buscando impor aquela concepção da autoridade que analisamos acima. $\mathrm{Na}$ metáfora do autoritarismo socialmente implantado pelo Estado e pela sociedade aparecem como decisivas aquelas transformações que conduzem à conformação de subjetividades ao "nível molecular"(6), num duplo movimento, porque, como argutamente assinala O'Donnell no seu comentário do artigo de Roberto da Matta "Você sabe com quem está falando?...", este autor "mostra núcleos de relacionamento, de dimensões de ordem e desordem que reaparecem, transmutados mas reconhecíveis, em cenários mais globais" (O'Donnell, 1986, p. 134). Curiosamente, de alguma maneira a antecipação de Da Matta levanta a questão da relação entre os níveis macro e micro de um sistema (social) extremamente complexo em termos quase topológicos, o que nos leva imediatamente a perguntar-nos sobre as "condições" do reaparecimento desses núcleos de relacionamento. $\mathrm{O}$ elemento complicador deste enfoque encontra-se no fato de que necessariamente temos que considerar um sistema extremamente complexo, com todas as limitações que isso implica. Nas ciências humanas, temos que nos conformar, como afirma O'Donnell, com saltos do micro ao macro que certamente somos incapazes de defender com razoável rigor $(1986$, p. 131), como pode ser atestado pela enumeração dos intentos realizados nesse sentido (idem, nota 14), mas que repesentam esforços de uma necessidade que não pode ser contestada.

Agora podemos retomar algumas facetas comparativas que O'Donnell trabalha em nível micro entre Brasil e Argentina. Depois de assinalar que, talvez devido a esse
Não encontramos na Argentina uma siłuação semelhante à que no Brasil justifica a frase "Eu já fui negro e sei o que isso significa" (Mário Filho), que, dita por um mulato celebérrimo, expressa a realidade subjetiva em uma consciência individual que reflete um verdadeiro "universo simbólico" construído pelo conjunto da sociedade brasileira

Menores abandonados, 1980

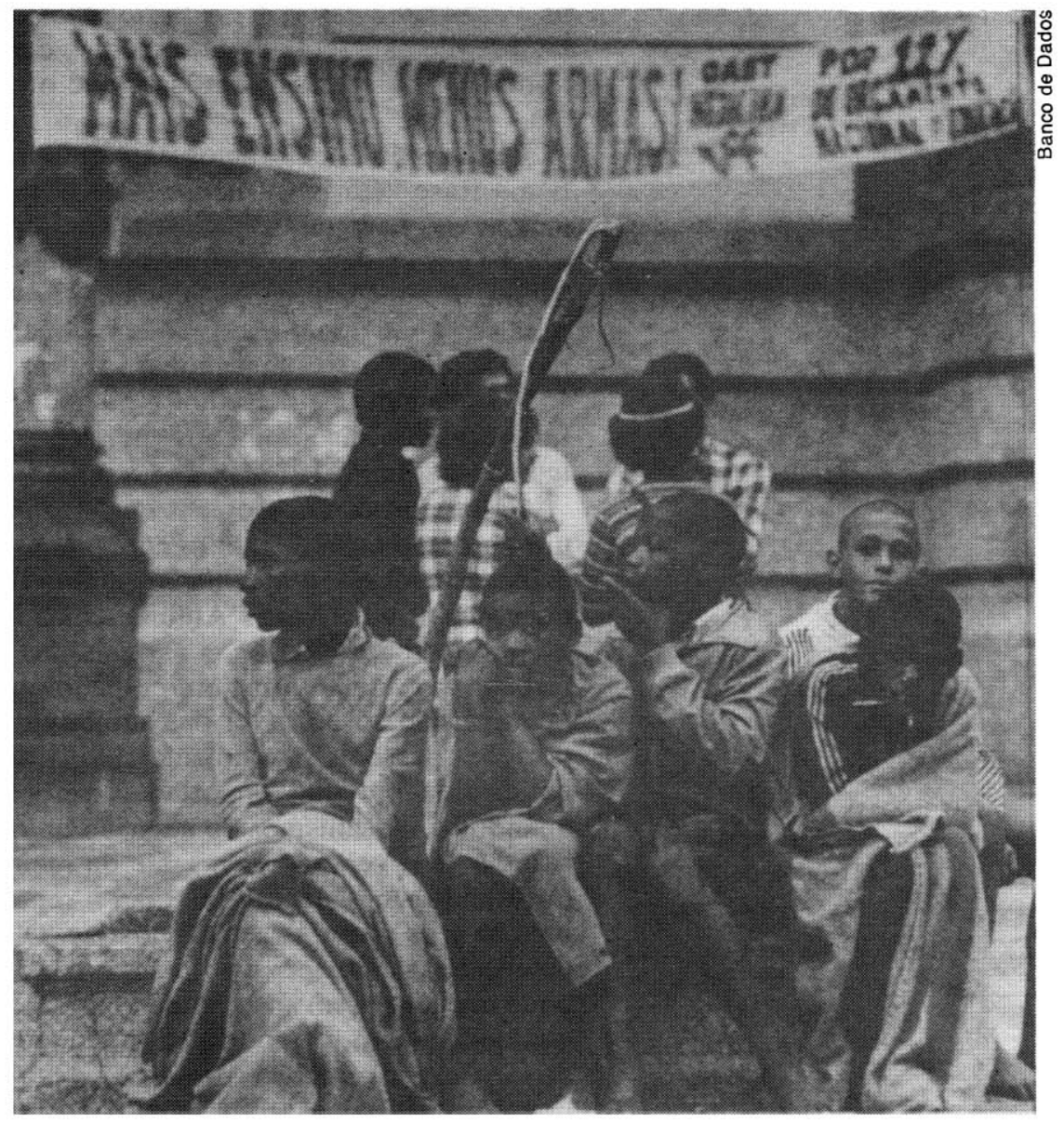


autoritarismo socialmente implantado pela sociedade e pelo Estado, a versão brasileira dos regimes autoritários tinha sido "menos" autoritária que os outros casos latino-americanos, no seu ensaio O’Donnell assinala a menor politização que caracteriza os setores populares brasileiros, condicionados por uma sociedade serialmente hierarquizada, com profundas demarcações, na qual os setores populares - ou classes que são menos classes - sempre mantiveram "o lugar deles", no contexto de uma ordem imposta por um conjunto de violências - favela, pobreza, desemprego, carência de direitos - que garantem a regulação da ordem tanto que permanentemente "reimpressas" pela violência policial, com padrões mais contínuos de repressão, configurando uma espécie de violência "protopolítica", de grande intensidade, mas que, diferentemente da Argentina, Uruguai ou Chile, nunca conheceu uma violência propriamente política permeando e penetrando a sociedade na magnitude das outras experiências latino-ar.ericanas.

Dentro do ensaio de O'Donnell articulado em torno do texto de Roberto da Matta do qual a síntese anterior não pretende refletir sua rica complexidade - chama a atenção o fato de que O'Donnell quase não toca num tema que, pensamos, expressa com muita força a problemática da transformação de contextos micro em macro: estamos nos referindo ao tema do racismo, que tem características muito diferentes no Brasil e na Argentina. Em primeiro lugar, vemos que no Brasil o problema racial - permita-nos colocar a questão nestes termos - está indissoluvelmente ligado à própria história nacional: não precisamos nos estender sobre isso. Na Argentina, com um fluxo de escravos muito menor, com a escravidão abolida formalmente em 1813, com uma população escrava e depois liberta dizimada nas guerras e nas epidemias (basicamente concentrada em alguns bairros de Buenos Aires, a população negra foi uma das vítimas prediletas da epidemia de febre amarela no fim do século passado), o problema racial foi reduzindo-se a um fato anedótico, minimizado ainda mais por uma imigração branca e européia. Na Argentina, como o próprio O'Donnell afirma em outro ensaio, o racismo assume a forma do "arrogante mito do país 'branco' e 'europeu' frente a uma América Latina índia e mulata" (1988, p. 46). Eventualmente, e isto é mais uma diferença, assume uma forma interna disfarçada mas de conteúdo nitidamente político com o advento do peronismo: os "cabecitas negras", o "aluvión zoologico", "los negros" figuram entre as metáforas prediletas que as classes médias e a oligarquia elaboram para colocar distância e estigmatizar os setores populares que o peronismo incorporava conflitivamente à cidadania.

Porém, não encontramos na Argentina uma situação semelhante à que no Brasil justifica a frase "Eu já fui negro e sei o que isso significa" (Mário Filho) que, dita por um mulato celebérrimo, expressa a realidade subjetiva em uma consciência individual que reflete um verdadeiro "universo simbólico" construído pelo conjunto da sociedade brasileira. E aqui voltamos finalmente ao tema que nos perturbava no início de nossas reflexōes sobre o autoritarismo socialmente implantado, ou seja, em que medida o domínio das relações pessoais como local privilegiado para o preconceito (da Matta, 1978, p. 155) se espalha pelo conjunto da sociedade brasileira, inclusive pelos setores mais desfavorecidos e discriminados, numa perversa reprodução da diferenciação contínua dos iguais (da Matta, 1978, p. 148 e nota 5).

Voltando por um momento à Argentina, neste diálogo crispado que pretende constituir-se como ensaio, cabe recordar uma das instâncias mais marcantes e provavelmente mais dramáticas vividas na Argentina dos anos 1976 a 1983. Estou me referindo à tantas vezes ouvida frase "Alguma coisa deve ter feito" por ocasião de alguma referência a uma pessoa detida ou - as mais das vezes - seqüestrada e desaparecida. Esta transformação de uma vítima em culpado com relação a uma ordem arbitrária e imprevisível operava não só ao nível das subjetividades - poderíamos falar aqui novamente de disposições pessoais socialmente significativas -, mas assumia características mais amplas na medida em que importantes setores recorriam a esse mecanismo de justificação quando os mecanismos de negação da realidade não mais funcionavam. Na verdade, verifica-se um verdadeiro resgate da racionalidade do sistema operante, resgate que se ia infiltrando simultaneamente com a repressão sistemática, atingindo os âmbitos de socialização e as próprias subjetividades. O que resulta estarrecedor nestes casos é como em determinadas situações o "universo simbólico" acaba articulando-se de maneira tal que pode conceber sem solução de continuidade a necessidade imperiosa de uma ordem - de qualquer ordem, como afirma O'Donnell, tamanho era o sentimento de caos - e a retirada imediata de qualquer limite normativo para essa mesma ordem, o que implica na prática a anulação nas consciências individuais dos sujeitos punidos como portadores de 


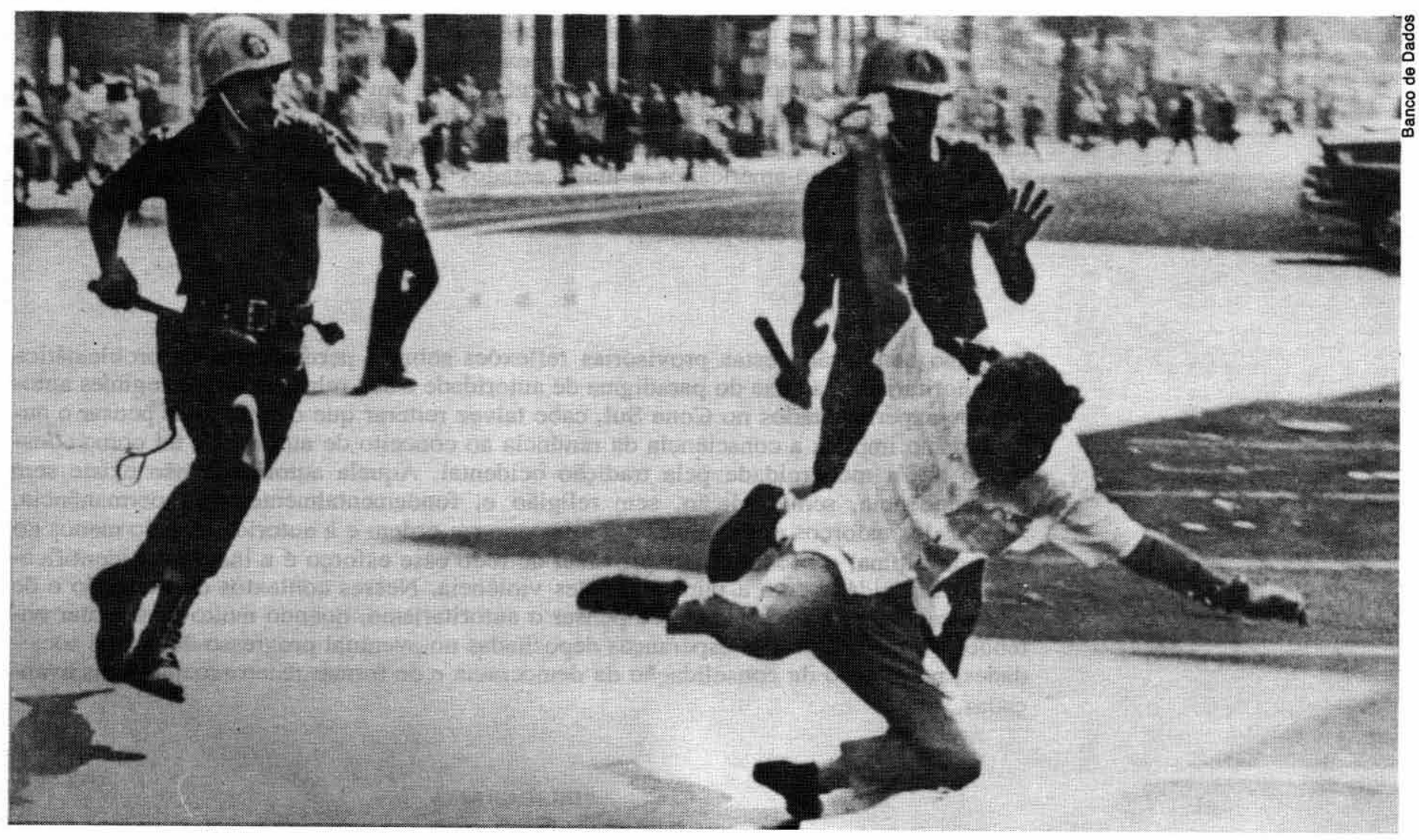

direitos. Ato seguido, seguia-se a eliminação física dos sujeitos, desaparecimento previamente convalidado nas subjetividades.

A outra cara do "Alguma coisa deve ter feito" ê uma espécie perversa do "E eu com isso?", que ratifica socialmente a fratura da sociedade, não mais para ridicularizar a hierarquia, mas para afirmar a presença do terror sobre o cotidiano da indefinição das condutas sancionáveis, sempre sujeitas a novos e imprevisíveis golpes. Talvez nunca como nestas circunstâncias os argentinos tiveram tanto que mobilizar suas energias para as fronteiras de si mesmos - para recuperar a metáfora de Ortega y Gasset -, relegando a sociabilidade para os limites da mera sobrevivência.

Essa transformação da vítima em culpado é bem conhecida também no Brasil. Neste caso, são outros os mecanismos, e passam muito mais pelo plano de "uma cultura jurídica dominante contaminada pelo elitismo e pelo particularismo e que define, no plano das regras formais, classes diferentes de cidadania" (Paixão, 1988, p. 191). Aqui novamente encontramos a sociedade tão minuciosamente hierarquizada de que nos falava O'Donnell. As consciências individuais geralmente nem chegam a perceber o que está acontecendo, à diferença com o caso argentino, onde o descompromisso precisou ser assumido ao nível individual, com as conseqüências de todos nós conhecidas quando o terror e os crimes do processo autoritário foram julgados.

Abundam os exemplos no Brasil do que falávamos acima: não só nos fatç de violência da vida cotidiana, que nos fornecem inúmeros casos, mas nos mecanismos que a discriminação sabe elaborar e decantar até assumir características de verdadeiros estig$\operatorname{mas}^{(7)}$.

\section{A RePresentaÇão ESQUizofrêniCA DA ORDEM}

No trabalho de Paixão citado acima, o autor analisa os dados de uma pesquisa realizada em Recife sobre atitudes em relação ao crime e à polícia ${ }^{(8)}$ e manifesta-se surpreso pelo apoio à "ordem" como estratégia de controle social em "todos" os níveis de renda e pelo radicalismo das penas que contam com o apoio dos grupos de baixa renda (Paixão, 1988, p. 192). Situações semelhantes poderão ser encontradas em muitos lugares
Repressão policial em manifestaçấo de rua, 1972
7 Para um panorama da desigualdade racial desde o ponto de vista da 'emografia, veja-se Berquo (1988), vastro (1990), Bercovich (1987), Garcia de Oliveira et al. (1985).

8 Trata-se da pesquisa e o artigo de Luciano de Oliveira e Aftonso Pereira "A polícia na boca do povo e a percepçăo social da violência", Recife, Fundaçăo Joaquim Nabuco, 1986, mimeo.

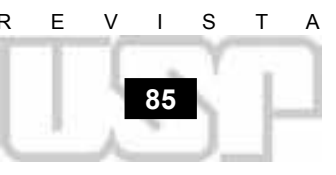


no Brasil, e colocam problemas interessantes para a ciência política, relacionados muitas vezes com nossa discussão prévia. Por exemplo: sobre que fundamentos cabe esperar em situações como as descritas a emergência de um princípio que legitime a coerção? Cabe esperar alguma coisa diferente da restauração da ordem pela identificação imediata da autoridade com a violência? A tendência ao colapso do Estado que ameaça alguns paŕses latino-americanos e ainda estados brasileiros pode estar acompanhando necessariamente a percepção esquizóide da ordem - sem aspas - e da identificação inevitável de autorictas com potestas.

Como conclusão destas provisórias reflexões sobre a permanência da problemática do autoritarismo, a crise do paradigma de autoridade e sua relação com os regimes autoritários experimentados no Cone Sul, cabe talvez reiterar que o esforço de pensar o autoritarismo implica a consciência da renúncia ao conceito de autoridade tal como constrứdo até a modernidade pela tradição ocidental. Aquela autoridade não existe sem transcendência, sem tradição, sem religião e, fundamentalmente, sem permanência. Apesar dos esforços dos regimes em reinstaurar a ordem e a autoridade, pelo menos no caso da última, o produto mais provável de todo esse esforço é a inevitável identificação da autoridade com a pura e simples violência. Nesses contextos de transição e de mudanças surge a necessidade de pensar o autoritarismo, quando muito para tentar entender o fundamento das esperanças depositadas no eventual progresso de nossas sociedades, na direção da consolidação da democracia e de formas macrossociais mais avançadas.

\section{BIBLIOGRAFIA}

ALTAMIRANO, Carlos. "Tema con variaciones", in Plural, no 1. Buenos Aires, Fundacion'n Plural, set./1985. ARENDT, Hannah. "What is authority?", in Between Past and Future. Penguin Books, New York, 1977.

BARRAT, Ernest S. "The Authoritarian Personality: A Proposed Systems Theory Analysis", in The High School Journal, fev.-março/1985.

BERCOVICH, Alicia. Fecundidade da mulher negra: constatações e questöes. Campinas, NEPO/UNICAMP, 1987 (Textos NEPO 11).

BERGER, P. e LUCKMANN, T. La construcción social de la realidad. Buenos Aires, Amorrortu, 1989.

BERQUÓ, Elza. "Demografia da desigualdade. Algumas consideraçốes sobre os negros no Brasil, in Novos Estudos Cebrap, no 21, julho/1988, pp. 74-84.

BISSERIER, Luis M. "El terror", in Conjetural, no 16, Buenos Aires, agosto/1988.

CAMPBELL, John B. "An Analysis and Demonstration of the Utility of Authoritarianism", in The High School Journal. Fev-março/1985.

CASTRO, Mary G. Female Heads of Household, Racism and Ageism in Brazil. Apresentado no Seminário Internacional Sobre Desigualdade Racial no Brasil Contemporâneo. Belo Horizonte, 1990, mimeo.

DA MATTA, Roberto. Carnavais, malandros e heróis. Rio de Janeiro, Zahar, 1978.

GALLI, Carlo. Modernita. Categorie e profili Critici. Bologna, Il Mulino, 1988.

GARCIA DE OLIVEIRA, Lúcia E. et alii. O lugar do negro na força de trabalho. Rio de Janeiro, Fundação IBGE, 1985.

GUATTARI, F. e ROLNIK, S. Micropolitica. Cartografias do desejo. Petropolis, Vozes, 1986.

O'DONNELL, G. "E eu com isso? Notas sobre sociabilidade e política na Argentina e no Brasil", in O’DONNELL, G. Contrapontos. Autoritarismo e democratização. São Paulo, Vértice, 1986

“Argentina: a macropolítica e o cotidiano", in Lua Nova, vol. 4, n² 2. São Paulo, abril-junho/1988.

"Situaçōes. Microcenas da privatização do público em São Paulo", in Novos Estudos Cebrap, n 22.

São Paulo, outubro/1988.

- "Transiçôes, continuidades e alguns paradoxos", in REIS F. W. e O'DONNELL, G. A democracia no Brasil. Dilemas e perspectivas. São Paulo, Vêrtice, 1988.

"Hiatos, instituiçöes e perspectivas democráticas", in REIS, F. W. e O'DONNELL, G., op. cit.

O’DONNELL, G. e GALLI, C. Adaptations to Social Change at the Micro-level. Outubro/1979, mimeo.

OESTERREICH, Detlef. “Authoritarianism: The End of a Concept?", in The High School Journal. Fev.-marÇo/1985.

ORTEGA Y GASSET, José. "Meditación del Pueblo Joven y Otros Ensayos sobre America”, in Revista de Occidente. Madri, Alianza Editorial, 1981.

PAIXĀO, Antonio Luiz. "Crime, controle social e consolidação da democracia: as metáforas da cidadania", in REIS, F. W. e O’DONNELL, G. A democracia no Brasil. Dilemas e perspectivas. São Paulo, Vértice, 1988.

PINHEIRO, Paulo S. "Violência e cultura", in LAMOUNIER, B. et alii (eds.). Direito, cidadania e participaçāo. São Paulo, T. A. Queirós, 1981.

STOPPINO, Mário. "Autoridade. Autoritarismo", in BOBBIO, N., PASQUINO, G. e MATTEUCI, N. (eds.). Dicionário de política. São Paulo, 1986. 